\title{
Zopiclone Intoxication: Value of Electroencephalography in the Emergency Room
}

\author{
Clemens Bloetzer $^{\mathrm{a}} \quad$ Antonio Carota $^{\mathrm{a}}$ Marc Augsburger ${ }^{\mathrm{b}}$ Paul-André Despland ${ }^{\mathrm{a}}$ \\ Andrea O. Rossetti ${ }^{\mathrm{a}}$ \\ ${ }^{a}$ Service de Neurologie, ${ }^{b}$ Institut Universitaire de Médecine Légale, Centre Hospitalier Universitaire Vaudois, \\ Lausanne, Suisse
}

Dear Sir,

Patients with new-onset stupor represent a common challenge in the emergency room. When etiology remains undetermined on the basis of clinical examination, neuroimaging, blood and urine workup, further investigations are mandatory. The following observation illustrates how electroencephalography (EEG) may point to the diagnosis of drug toxicity, even when results of standard toxicological urine immunoassays are negative.

\section{Case Report}

A 26-year-old man, known for personality disorder and previous depression, was admitted to the emergency department because of unusual profound sleepiness in the morning (arousal only for few seconds following intense stimulation). Although he was known to take zopiclone occasionally for insomnia, his girlfriend categorically denied illicit drug or medication ingestion in the last $48 \mathrm{~h}$. Apart from stupor, neurological examination did not reveal any pathological findings; his pupils were slightly mydriatic and reactive. Hematology, blood electrolytes, renal and hepatic tests, glucose, C-reactive protein, thyroid function, blood ammonium and CSF analysis were unremarkable; thiamine administration was uneventful.
Standard urine toxicological immunoassays for benzodiazepines, barbiturates, cannabinoids, opiates, methadone, cocaine, buprenorphine, propoxyphene, LSD and amphetamines were negative; serum ethanol level was undetectable. There were no abnormal findings on brain CT with perfusion and venous angiography. EEG on admission showed essentially normal-structured sleep stage II, with symmetrical spindles and $\mathrm{K}$ complexes; following nociceptive stimulation, a poorly sustained $\alpha$-rhythm appeared; during the whole recording, abundant, diffuse superimposed $\beta$ (fast)-activity was noted (fig. 1a). A flumazenil test was not performed to avoid provoked seizures.

Stupor recovered spontaneously within $24 \mathrm{~h}$, and a second EEG 6 days later was normal, with minimal superimposed fast activity (fig. 1b). Considering these EEG findings, we performed a serum gas chromatography/mass spectrometry and liquid chromatography UV on the serum sample drawn on admission; this revealed a toxic level of zopiclone $(250 \mu \mathrm{g} / \mathrm{l}$; norm $<100 \mu \mathrm{g} / \mathrm{l}[1])$.

\section{Discussion}

This report highlights the value of EEG performed emergently in diagnosing drug toxicity when the routine workup is inconclusive. In fact, prominent EEG $\beta$-activity suggested the presence of a GABA-ergic drug and prompted further diagnostic procedures.

Abundant fast EEG activity entails a broad differential diagnosis: commonly, it results from GABA-ergic agents (benzodiazepines, barbiturates, low-dosed propofol and isoflurane) or other drugs (ethanol, cocaine, opiates, tricyclic antidepressants, high-dosed chloral hydrate). However, it may be also rarely observed with fever, hyperthyreosis, brain stem lesions or migraine $[2,3]$. In exceptional circumstances, diffuse $\beta$-EEG activity might be compatible with recurrent idiopathic stupor, a rare disorder characterized by sleep periods lasting hours to days. Etiologically, acute accumulation of endogenous ligands (endozepines) to the brain benzodiazepine GABA receptor is postulated [4-7].

Zopiclone is a nonbenzodiazepine hypnotic acting through $\mathrm{GABA}_{\mathrm{A}}$ receptor modulation, whose effects on human EEG have been described only following therapeutic administration to healthy volunteers. Two studies showed an increment of slow-wave sleep that was more consistent than with benzodiazepines $[8,9]$, whereas

\section{KARGER}

Fax +4161306 1234 E-Mail karger@karger.ch www.karger.com
(C) 2007 S. Karger AG, Base 0014-3022/07/0584-0246\$23.50/0

Accessible online at: www.karger.com/ene
Dr. Andrea O. Rossetti

Service de Neurologie

CHUV-BH07

CH-1011 Lausanne (Switzerland)

Tel. +41 21314 1220,Fax +4121314 1190,E-Mail andrea.rossetti@chuv.ch 
Fig. 1. a EEG during brief wakefulness on admission, with diffuse $16-$ to $18-\mathrm{Hz} \beta$ superimposed on poorly sustained 10 - to $12-\mathrm{Hz}$ posterior $\alpha$. Stage II sleep disclosed abundant spindles and persistent $\beta$ rhythms. (Longitudinal bipolar 'long distance' montage, $70 \mu \mathrm{V} / \mathrm{cm}, 30 \mathrm{~mm} / \mathrm{s}$, HFF $70 \mathrm{~Hz}$, LFF $0.5 \mathrm{~Hz}$.) b EEG during wakefulness 6 days after admission, showing a well-developed, low-voltage $12-\mathrm{Hz} \alpha$-activity, but almost no superimposed $\beta$. (Longitudinal bipolar 'long distance' montage, $70 \mu \mathrm{V} / \mathrm{cm}, 30 \mathrm{~mm} / \mathrm{s}$, HFF $70 \mathrm{~Hz}, \mathrm{LFF}$ $0.5 \mathrm{~Hz}$.)

wakefulness EEG displayed $\alpha$-activity decrease and $\beta$-activity increase [9]. Our report shows that diffuse $\beta$-EEG activity represents a prominent feature of zoplicone intoxication, in analogy with benzodiazepines.

As prescription of atypical GABA-ergic agents is gaining in popularity, the diagnosis of related toxicity may challenge emergency physicians. In fact, standard urine immunoassays, which are commonly available in emergency rooms, are not sensitive to these drugs (zopiclone, zolpidem), as well as lorazepam and bromazepam [10]. This observation shows that in these circumstances EEG represents a useful, noninvasive tool to orient early diagnostic procedures.
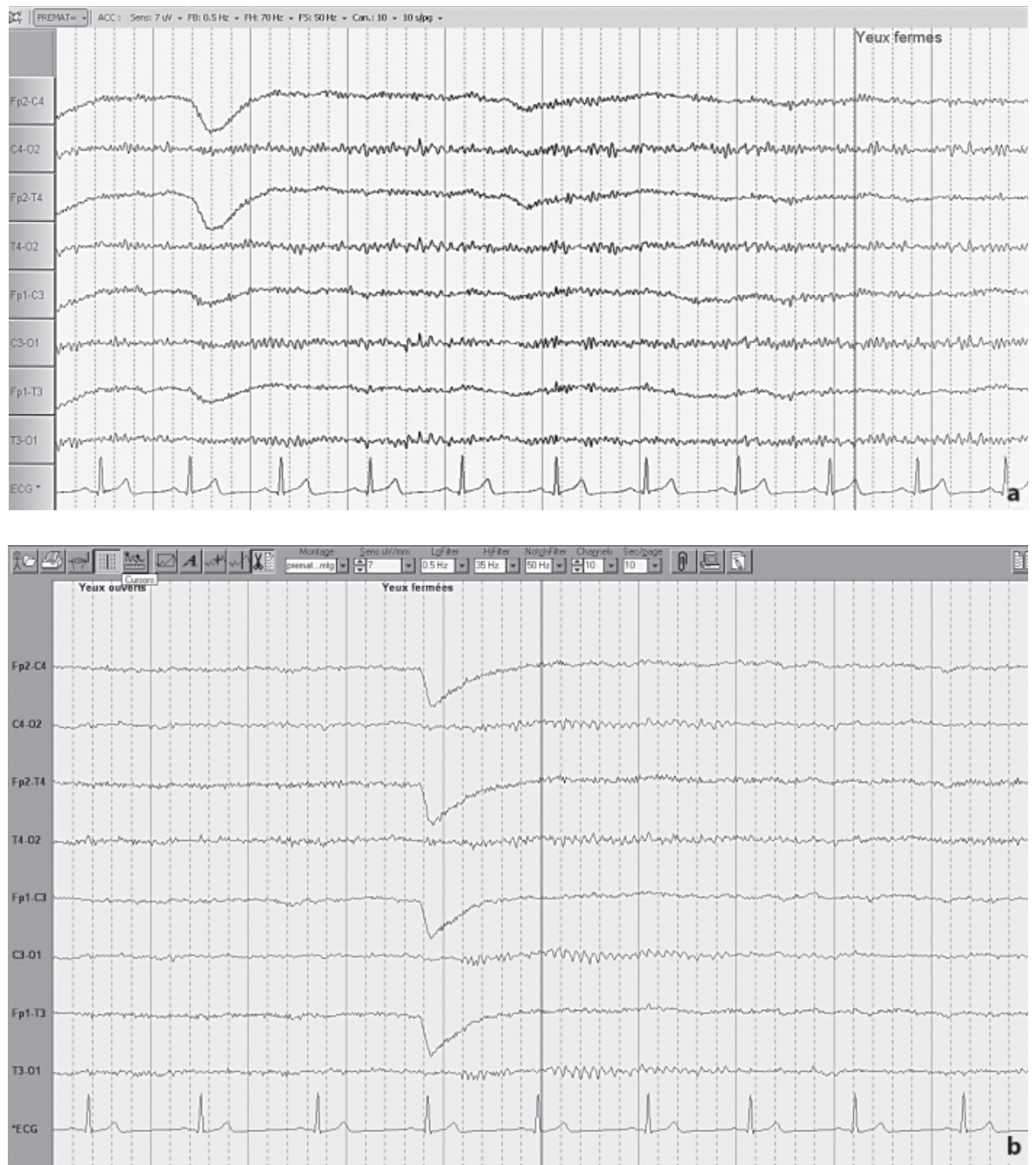

\section{References}

1 Schulz M, Schmoldt A: Therapeutic and toxic blood concentrations of more than 800 drugs and other xenobiotics. Pharmazie 2003;58:447-474.

2 Fish BJ: Fish \& Spehlmann's EEG Primer Amsterdam, Elsevier, 1999, pp 411, 416, 422.

3 Plum F, Posner JB: The Diagnosis of Stupor and Coma, ed 3. Philadelphia, FA Davis, 1980.

4 Cortelli P, Avallone R, Baraldi M, Zeneroli ML, Mandrioli J, Corsi L, et al: Endozepines in recurrent stupor. Sleep Med Rev 2005;9: 477-487.

5 Huberfeld G, Dupont S, Hazemann P, Adam C, Baulac M, Pierrot-Deseilligny C: Stupeur récurrente idiopathique chez un patient: imputabilité des benzodiazépines endogènes ou exogènes? Rev Neurol (Paris) 2002;158: 824-826.
6 Lugaresi E, Montagna P, Tinuper P, Plazzi G, Galassi R, Wang TC, et al: Endozepine stupor. Recurring stupor linked to endozepine4 accumulation. Brain 1998;121:127-133.

7 Tinuper P, Montagna P, Cortelli P, Avoni P, Lugaresi A, Schoch P, et al: Idiopathic recurring stupor: a case with possible involvement of the gamma-aminobutyric acid (GABA) ergic system. Ann Neurol 1992;31:503-506.

8 Jovanovic UJ, Dreyfus JF: Polygraphical sleep recordings in insomniac patients under zopiclone or nitrazepam. Pharmacology 1983;27(suppl 2):136-145

9 Yamadera H, Kato M, Tsukahara Y, Kajimura N, Okuma T: Relationship between the effects of a hypnotic drug, zopiclone, on polysomnography and on daytime EEGs. Neuropsychobiology 1997;35:152-155.

10 Lugaresi E, Montagna P, Tinuper P, Plazzi G, Gallassi R: Suspected covert lorazepam administration misdiagnosed as recurrent endozepine stupor. Brain 1998;121:2201. 